\title{
Representação social: Uma revisão teórica da abordagem
}

\author{
Social representation: A theoretical review of the approach \\ Representación social: Una revisión teórica del enfoque
}

Recebido: 07/05/2021 | Revisado: 12/05/2021 | Aceito: 17/05/2021 | Publicado: 04/06/2021

\author{
Karine Nogueira de Sousa \\ ORCID: https://orcid.org/0000-0001-8738-6812 \\ Universidade de Ciências Empresariais e Sociais, Argentina \\ E-mail: karinen.psico@gmail.com \\ Priscila Cristiane de Souza \\ ORCID: https://orcid.org/0000-0001-5084-6838 \\ Universidade de Ciências Empresariais e Sociais, Argentina \\ E-mail: priscilacristianemedeiros@gmail.com
}

\begin{abstract}
Resumo
O presente artigo objetiva apresentar a Teoria das Representações Sociais, criada por Serge Moscovici em 1961, bem como as contribuições que diversos autores criaram a partir dela. Este estudo faz um revisão bibliográficas por meio de artigos científicos e livros de diversos estudiosos que buscam compreender e explicar a abordagem a partir da prática diária do ser humano, sendo esta uma leitura da realidade constituída por meio dos pensamentos dos indivíduos de um determinado grupo, que juntos produzem um núcleo central, onde são traduzidos suas ideias, pensamentos e a compreensão sobre um determinado objeto ou fenômeno. A Representação Social como abordagem, possui grande importância nos estudos onde se busca a compreensão de fenômenos sociais para criar mecanismos adequados de atendimento as necessidades de determinado grupo. O presente artigo traz ainda a contextualização histórica e epistemológica da teoria, os processos de objetivação e ancoragem, a função da representações sociais e as formas de conhecimento consensuais e reificadas, além das abordagens teóricas: cultural, estrutural e societal.
\end{abstract}

Palavras-chave: Teoria das representações sociais; Pensamento coletivo; Núcleo central; Leitura da realidade.

\begin{abstract}
This article aims to present the Theory of Social Representations, created by Serge Moscovici in 1961, as well as the contributions that several authors have created from it. This study makes a bibliographic review through scientific articles and books of several scholars who seek to understand and explain this approach of the daily practice of the human being, which is a reading of reality constituted through the thoughts of individuals from a particular group, which together produce a central core, where their ideas, thoughts, understanding about a particular object or phenomenon are translated. Social representation as an approach has great importance in studies that seek to understand social phenomena in order to create appropriate mechanisms to meet the needs of a given group. This article also brings the historical and epistemological contextualization of the theory, the processes of objectification and anchoring, the function of social representations and the forms of knowledge being consensual and reified and beyond its theoretical approaches: cultural, structural and societal.
\end{abstract}

Keywords: Social representations theory; Collective thinking; Central core; Reading reality.

\section{Resumen}

Este artículo pretende presentar la Teoría de las Representaciones Sociales, creada por Serge Moscovici en 1961, así como las aportaciones que varios autores han creado a partir de ella. Este estudio hace una revisión bibliográfica a través de artículos científicos y libros de varios estudiosos que buscan entender y explicar este enfoque de la práctica cotidiana del ser humano, siendo este una lectura de la realidad constituida a través de los pensamientos de los individuos de un grupo particular, que en conjunto producen un núcleo central, donde se traducen sus ideas, pensamientos, comprensión sobre un objeto o fenómeno particular. La representación social como enfoque tiene gran importancia en los estudios que buscan comprender los fenómenos sociales para crear mecanismos adecuados para satisfacer las necesidades de un grupo determinado. Este artículo también aporta la contextualización histórica y epistemológica de la teoría, los procesos de objetivación y anclaje, la función de las representaciones sociales y las formas de conocimiento siendo éstas consensuadas y reificadas y más allá de sus enfoques teóricos: cultural, estructural y societal.

Palabras clave: Teoría de las representaciones sociales; Pensamiento colectivo; Núcleo central; Lectura de la realidad. 


\section{Introdução}

Os estudos sobre a representação social tem sido crescentes desde sua publicação, na tentativa de explicar e compreender fenômenos sociais, por meio de situações comuns do cotidiano, que quando passados de uns para outros se tornam verdades. São conhecimentos naturais dos indivíduos que são transmitidos de geração para geração, são opiniões e ideias de pessoas de um grupo sobre determinado fenômeno ou acontecimento. A representação é um conhecimento real, formado pelo senso comum entre um grupo de indivíduos, o conhecimento se torna uma representação a partir do momento que se torna uma verdade para todos os membros que compõem o grupo (Jodelet, 2001).

Ferreira (1975) afirma que a representação social é uma espécie de crença regional de um povo, baseado nas suas tradições, é o conhecimento criado por sentidos, pela imaginação, memória, é uma reprodução do pensamento. Esta abordagem teve contribuição de diversos autores, começando em 1985, com a obra A alma das Multidões de Gustave Le Bon, onde explica sobre a psicologia das multidões, afirmando que um pensamento particular se apaga em situações de grupo. A alma coletiva não depende de semelhanças ou diferenças entre as pessoas que pertence ao grupo, ela se despertam e tornam uma ação coletiva entre os sujeitos do grupo.

Quando estamos entre outras pessoas discutindo uma determinada ação, tendemos a pensar de forma semelhante aos demais indivíduos do grupo, passando a ser um pensamento coletivo. Os sentimentos podem ser transformados tanto para melhores quanto para piores. O termo multidão que aborda o autor está relacionando a uma ideia diferente da que normalmente usamos, ele se refere a uma ideia única que guia todos do grupo (Gustave Lebon, 1895).

Ainda neste contexto, Freud (1921- 1979) apresenta a psicologia das massas, teoria que trata de indivíduos como membros de uma linhagem, de um grupo, de um povo, que faz parte de uma multidão que se organiza para uma dada finalidade e período de tempo.

Freud (1921 - 2011), pontua que uma massa é uma quantidade de indivíduos que pensam coletivamente, quanto mais características o grupo tiver em comum, mais fácil de se ter uma massa psicológica, e desta forma identificar evidências e manifestações de forma coletiva.

Para McDougall (1920) "massas" é uma condição para chamar uma "vida mental coletiva", o autor entende que o desenvolvimento dos indivíduos é realizado através da participação de todos, voltados aos mesmos elementos, como exemplo temos as tradições e costumes de um determinado povo ou região.

Para Milgram e Toch (1969) os movimentos sociais podem ser considerados um desenho do comportamento em massa, independente do seu tamanho, o grupo busca expressar os mesmos desejos e as mesmas angústias, um grupo único e sólido possui os mesmos pensamentos, objetivos e anseios, dentre os quais se destaca a busca por solução de problemas para todos os envolvidos.

Canetti (1995) afirma a ideia de que massas é um recurso do indivíduo para se libertar do medo do outro e do desconhecido, pois iguala os sujeitos, permitindo que se sintam seguros.

Na construção da Teoria das Representações Sociais também houve a contribuição da sociologia e da antropologia, ao falar sobre as representações coletivas, marcado pelas teorias de Émile Durkheim e Lévy-Bruhl, referente a realidade coletiva (Bertoni, Galinkin, 2017).

Durkheim (1987) entende que as representações coletivas expressam a maneira que o grupo se enxerga em relação a objetos que os afetam, que traduz os seus ideais e pensamentos. Se a representação está constituída de sujeitos que pensam de forma diferente, as representações não poderão expressar os mesmos objetivos nem os mesmos sujeitos, desta forma não exprimem as mesmas causas entre eles.

As representações coletivas abriram espaços para originar as representações sociais. Segundo Oliveira (1999) elas são formadas por "práticas sociais do grupo e não apenas do 'se pensar"”. O autor afirma que a representação é formada pelo conjunto 
de ações cotidianas de um grupo, desenvolvidas por meio de seu modo de interpretar o mundo, de viver e pensar que se assemelham entre os indivíduos.

Outra importante corrente que contribuiu na formação da representação como teoria, foram os estudos da psicologia construtivista de Jean Piaget e de Lev Vygotsky. A abordagem construtivista entende que o ser humano está em constante transformação e aprendizado, sendo o sujeito responsável pelo seu próprio desenvolvimento, que se constrói gradativamente (Bertoni, Galinkin, 2017).

Piaget (1959) aborda sobre o construtivismo explicando que o conhecimento não se acaba, ele está constantemente sendo aperfeiçoado pelo engajamento dos indivíduos. O conhecimento parte do comprometimento do indivíduo com o meio em que ele pertence, o indivíduo atua sobre o objetivo em busca de transformação, e quando transformado a ação se torna acomodadora, retornando a necessidade de mudanças.

O autor pontua que a ação acomodadora é formada pelo instrumento de assimilação e o conhecimento é construído pela interação entre os meios físico e social (Becker, 2009, como citado em Piaget, 1959, p. 2).

A assimilação é o processo onde são inseridas novas informações na estrutura cognitiva do indivíduo, formação de experiências, conteúdos e ideias se organizam na área de conhecimento, na estrutura mental do sujeito. É a modificação de uma estrutura cognitiva já existente, através do esforço constante de adaptação, alterando os esquemas adquiridos e adequando a um novo conteúdo com base a uma estrutura mental pré-existente (Piaget, 1959).

Vygotsky (1999), afirma que o processo de desenvolvimento consiste em usar os signos internos. As representações produzidas pela nossa mente definem os objetos que entendemos como mundo real, pois estes signos que possuímos são como as marcas exteriores que simulam as situações e eventos.

Na concepção do autor, os conhecimentos "internalizados" são base para compreensão de novos objetos, as marcas internas ajudam a reformular os conhecimentos externos, passando a ser compreendidos pelo processo de assimilação.

A TRS teve também a contribuição de Gilbert Durand (1984) representante do estudo imaginário, ele procurou traduzir a realidade através dos significados, na sua concepção, o significante impõem sentido e significado, representando assim algo ou algum objeto.

A psicologia social entende as representações sociais como um fenômeno, que substitui o coletivo pelo social, deixando de ser apenas um conceito que explica os acontecimentos e crenças de um grupo e se torna um fenômeno que exige explicação, e desta forma produz um novo conhecimento. Arruda (2002) reforça esta posição ao dizer que a realidade social construída e o saber são construções cotidiana do indivíduo, e não são desligadas da inscrição social.

\section{Metodologia}

O presente artigo se constitui por uma revisão bibliográfica de caráter analítico a respeito da Teoria das Representações Sociais enquanto abordagem para compreensão do comportamento de determinados grupos. Segundo Pereira (2018) o artigo científico permite realizar uma revisão da literatura de forma simplificada, permitindo melhor compreensão do tema, de forma que concentra diversos autores que abordam o mesmo assunto. A partir desta premissa iniciamos o levantamento dos materiais, que se deu no período de 01 a 30 de março de 2021, foram utilizadas como base de dados para a pesquisa Scientific Eletrônic Library Online (SCIELO), Literatura Latino-Americana e do Caribe em Ciências da Saúde (LILACS), e National Library of Medicine (PUBMED). Como critério para a inclusão utilizamos: artigos que apresentassem a epistemologia das representações sociais, artigos que discorressem sobre as funções, tipos e abordagens, independente do ano de publicação, pois nos levantamentos iniciais percebemos que os estudos mais antigos apresentam maior detalhamento dos processos de construção da teoria em questão. Desta maneira estão presentes estudos desde 1959 a 2020. 
A partir da seleção dos materiais de acordo com os critérios de inclusão apresentados, se iniciaram os passos para construção do artigo: realizamos um leitura seletiva e exploratória para a inserção de estudos que melhor se adequassem a ideia do artigo, seguido de uma leitura com análise mais aprofundada dos mesmos com a busca por alguns livros citados pelos autores, que nos trouxessem um aporte maior sobre o tema, e como conclusão realizamos a leitura interpretativa e a redação.

Ao final das etapas apresentadas, obtivemos um corpus do artigo selecionando os temas que mais apareceram por categorias, sendo elas: Teoria das Representações Sociais, Objetivação e ancoragem, Universos consensuais e universos reificados, Funções das Representações Sociais e Abordagens da Representação Social, que serão apresentadas a seguir.

\section{Teoria das Representações Sociais}

A Teoria das Representações Sociais foi criada por Serge Moscovici, considerado um dos fundadores da psicologia social. Ela traz um recorte e remodelagem das teorias de Émile Durkheim e Lévy-Bruhl, com as representações coletivas, tem a contribuição de Jean Piaget e de Lev Vygotsky com abordagem construtivista e de Gilbert Durand, com os estudo do imaginário, além de outros autores que no decorrer do tempo foram aprimorando o estudo da presente teoria.

Os primeiros registros de Moscovici sobre a teoria, foram registrados pela obra La Psicanalyse: son image et son public (1961), que tinha o objetivo de operacionalizar um conceito para trabalhar o pensamento social. Jesuíno, 2011, aponta também o objetivo de compreender como o conhecimento era transmitido por meio da comunicação para a produção de conhecimento, através de histórias e crenças compartilhada entre os indivíduos (Jesuíno, 2011). O autor entendia que a representação social é o acumulo de proposições, ações e avaliações que são organizadas pelos seus grupos de diferentes formas (Nogueira, Di Grillo, 2020).

Em 1976, foi realizada uma reformulação da teoria, visto que a primeira não foi bem aceita. A segunda foi aprofundada e apresentou diversas evoluções do autor o que enriqueceu o estudo. Moscovici estudava as percepções sociais e tinha como objetivo compreender como se atribuíam causas ao comportamento dos indivíduos. Nesta fase o pensamento do autor sobre o ser humano passou por uma mudança, indo da percepção de ser um animal racional para ser uma máquina de processamento, entendendo que o ser humano é pensante (Moscovici, 1982).

Jodelet (1994) conceitua a representação social, como forma de conhecimento elaborado e compartilhado entre determinados grupos, tendo objetivo prático na construção da realidade social. Abric (1994), entende que a representação se constitui da vivencia da realidade, por conversas e trocas de experiências, crenças e a maneira de interpretar acontecimentos do cotidiano, permitindo compreender e também explicar a realidade.

Jodelet (2005) pontua que, a construção da teoria das representações sociais está entre nós no cotidiano e se manifesta por saberes práticos dos sujeitos, na expressão da identidade, nas tradições e culturas, na forma e modo de viver, presente nos costumes. Para a autora "a representação é um guia para as ações sociais". (p. 135)

Duran (2006) afirma que, a representação social é a busca da compreensão da própria essência do homem, maneira de pensar, é portanto, uma forma de compreensão coletiva, saberes e ideias diferentes pessoas que compõem um grupo.

Segundo Lefebvre (1968) a representação é formada pela construção de conceitos de situações reais, tem como prioridade as representações econômicas, sociais e políticas de um grupo independente da classe social que pertence.

Moscovici (2012) pontua que a representação social é um maneira de conhecimento do indivíduo, tem o objetivo de compreender o comportamento e a comunicação, estimulando o diálogo entre os indivíduos, para manter uma relação entre sujeito e objeto.

Farias, Silva, JR e Medeiros (2020) as representações sociais é entendida como um conjunto e características do comportamento humano e do relacionamento com o ambiente, é a produção dos comportamentos sociais. 
Moscovici (1978) descreve que a representação é uma modo de conhecimento que tem a função de elaborar comportamentos e manter a relação entre as pessoas através da comunicação. Composta por expressões que se constituem por meio da linguagem e são representados por figuras ou objetos que produzem significações, comportamentos e conceitos, tornando o abstrato em comum. A representação é um saber prático organizado por um grupo de pessoas, que por pensarem de forma semelhante produzem um conhecimento consensual, baseado no conhecimento "senso comum" compartilhado entre eles. Portanto é uma expressão do conhecimento elaborado a respeito da realidade de um grupo.

Almeida e Santos (2011 apud Jodelet 1991), entendem que a representação social são expressões do senso comum, um conhecimento corrente, formado socialmente que é compartilhado pelas pessoas, é uma visão da realidade comum.

Para Abric (1994) a representação é constituída pelo conjunto de informações, opiniões, atitudes e crenças, sobre um determinado objeto, sendo construída esta ideia por meio da observação e da comunicação entre os indivíduos.

Jodelet (1989) pontua que as representações devem ser estudadas com base na análise dos elementos afetivos, mentais e sociais, pois eles se integram a linguagem e a comunicação e as relações sociais interferem nas representações sociais.

Para Tomé, Formiga (2020) as representações sociais são entendidas como opiniões individuais que são reelaboradas sobre um objeto social, que sofrem influências sobre a vida de cada pessoa, se constitui para satisfazer as necessidades e interesses de um grupo.

Sá (1998), compreende que a representação social é um fenômeno que está presente na prática social diária, pela cultura e comunicação, através dos nossos pensamentos, presente na relação social e está em constante adaptação na realidade, no modo de pensar e comportar dentro das instituições e grupo.

A teoria das representações sociais, se compõe por imagens, ideias, símbolos e conceitos que são gerados por crenças e ideias. Nos estudos de Moscovici elas apresentam legitimidade, são vias de assimilação do mundo concreto (Nogueira, Di Grillo, 2020).

Neste sentido, os autores supracitados enfatizam que a representação social é uma maneira de interpretar os acontecimentos e comunicar-se por meio do conhecimento, explicações, opiniões, crenças e ideias sobre um determinado fato ou fenômeno, elementos e vivências práticas que constituem a própria realidade, possibilita classificar e nomear os acontecimentos, tem objetivo de tornar familiar objetos desconhecidos, utilizando de dois processos, a ancoragem e objetivação.

\section{Objetivação e Ancoragem}

Na construção das representações sociais são considerados dois processos, a objetivação que é confeccionar um cenário e torna-lo familiar e a ancoragem, que possibilita a interpretação e comparação dos objetos, categorizando e rotulando, sendo possível classificar, nomear e representar pensamentos.

A objetivação é a fase em o que era abstrato se torna familiar e concreto, momento de cristalização das ideias. Moscovici (2005) afirma que é preciso repensar no conceito de uma imagem, pois tem o objetivo de descobrir a sua qualidade simbólica.

A objetivação se constitui por três elementos, sendo eles:

- A seleção e descontextualização que é o conjunto de informações dos indivíduos que retiram a partir de conhecimentos já existentes anteriormente, são eles os valores, tradições ou mesmo experiências;

- A formação do núcleo figurativo, que é uma construção do modelo figurativo, a criação do conceito;

- A naturalização dos elementos, onde os elementos são construídos e passam a ser identificados como elementos da realidade do objetivo.

Já a ancoragem é o processo pelo qual um objeto se torna familiar, transformando em conhecido algo cotidiano, de forma que influencia outras pessoas. "A Ancoragem é um processo que transforma algo estranho e perturbador, que nos intriga, 
em nosso sistema particular de categorias e o compara com um paradigma de uma categoria que nós pensamos ser apropriada". [...] “Ancorar é, pois, classificar e dar nome a alguma coisa”. (Moscovici, 2005, p. 61)

Este processo, assim como o anterior também é constituído de três elementos, sendo eles:

- A atribuição de sentido: onde se constitui o enraizamento do conhecimento e cria-se uma rede de significados por meio de outros conhecimentos pré-existentes. Momento onde é nomeado um novo objeto.

- A instrumentalização do saber: processo onde permite se ter um valor, tornando uma teoria de referência, permite a compreensão do mundo social.

- $\quad$ O enraizamento no sistema de pensamento: neste processo as representações preexistentes, se tornam familiares aos sujeitos, e transformam o conhecimento anterior, permite a classificação, comparação e categorização do novo objeto.

O autor descreve ainda duas operações sendo a assimilação e acomodação, a assimilação é um processo de inclusão de novos conhecimentos a outros que já existem, incluindo elementos a estrutura pré-existente. E a acomodação é a modificação de estruturas existentes ou a criação um novo esquema, uma nova forma de compreensão.

\section{Universos Consensuais e Universos Reificados}

Serge Moscovici no estudo da teoria das representações sociais, pontua que o conhecimento se constrói a partir de duas diferentes fontes denominadas de universos consensuais e reificados, são diversas por apresentarem intensões diferentes e não possuirem uma ordem (Arruda, 2002).

Para Arruda (2002), o universo consensual, é o conhecimento que chamamos de senso comum, construído pela socialização de ideias, baseado na relação e experiência cotidiana dos indivíduos de um mesmo grupo. Já o universo reificado, se origina dos saberes científicos, se constrói com o apoio de um profissional capacitado com conhecimentos técnicos e científicos, por meio de estudos e pesquisas, e se mantém por uma metodologia que o valida e objetiva retratar uma realidade independente da consciência dos indivíduos.

Os dois universos se relacionam e são indispensáveis. Pelo processo de socialização das ideias, juntos eles formam a realidade de um grupo e possibilitam a interpretação dos comportamentos deste (Arruda, 2002).

Moscovici (1994), entende que os universos de conhecimento consensuais e reificados possui três dimensões, sendo elas: a atitude, a informação e o campo de representação (imagem). A informação refere a organização dos conhecimentos sobre um determinado objeto, o campo de representação nos designa a uma imagem, criada por meio de características do objeto social, e a atitude, consiste na orientação global do objeto representado, quando cria a representação.

Moscovici (2001) afirma que a representação social é considerada ciência, por se constituir ou reconstituir a partir de relações sociais, transforma o conhecimento comum, e desta forma, influencia na nossa realidade, ela se repercute direta ou indiretamente nas atitudes do grupo, rotula um modo de agir e pensar sobre um determinado objeto e expressa os significados de diversas realidade do grupo a que pertence.

Pelo processo de socialização o conhecimento é moldado, adquire sua significação e roupagem. Por meio da comunicação entre os indivíduos se torna possível criar uma nova representação sobre uma realidade, fenômeno ou objeto. O conhecimento possui uma relação do indivíduo com o que se pretende conhecer, o objeto. Ambos são essenciais para a concretização do conhecimento. Por meio da representação social é possível identificar a percepção de um grupo sobre um determinado fato (Moscovici, 1978). 


\section{Funções das Representações Sociais}

As funções da representação social, contribuem na construção da realidade e são sustentadas por vários sujeitos de um mesmo grupo. Abric (2000) aborda sobre as 04 funções básica e essenciais da teoria, são elas:

A Função do saber: permite a compreensão da realidade, se constitui através do conhecimentos práticos, tendo como função compreender o senso comum e os saberes do individuais e grupais, permite a troca de experiências através da comunicação dos indivíduos.

A função identitária: possibilita a proteção das características individuais composta no grupo, possui o papel de controle social, sendo ela de grande importância por definir a identidade do grupo, está relacionada a marca de cada grupo, atributos, qualidade e suas particularidades. Cada grupo possui um estilo ou jeito de pensar, agir e entender a realidade que o cerca, este processo tem função de manter as característica de cada grupo com suas potencialidades e especificidades.

Função de orientação: composta por práticas sociais que direcionam o comportamento, funciona como um filtro das informações. É composta pelo direcionamento das ações dos indivíduos dentro do grupo, analisa as práticas e adequam quando necessário, seleciona e filtra informações que cabe ao grupo, orientam os sujeitos dentro das características que jugam serem pertinentes.

Função justificadora: opera com objetivo de justificar e explicar as escolhas e comportamentos dos sujeitos que pertencem ao grupo, definindo um padrão a seguir pelos sujeitos do grupo.

Abric (2000), afirma ainda que existe na representação social um núcleo onde é mais resistente as mudanças por estar ligado a história do indivíduo ou do grupo onde se estabelece a significação, consistência e permanência da representação.

Moscovici (1978) compreende que, a representação social é uma forma de conhecimento (modalidade) que tem a função de elaboração de comportamentos e estabelecer a comunicação entre os indivíduos.

Na concepção de Doise (1976-84) as representações sociais possuem três funções sendo a seleção, justificação e antecipação.

Na função seletiva está presente a centralidade dos conteúdos da representação, para manter uma relações entre os grupos, fazendo um filtro dos conteúdos que não são relevantes.

A função justificativa tem objetivo de expressar o conteúdo, que se vincula a uma imagem de outro grupo, criando e justificando um comportamento de rejeição do outro, sendo contrário do contexto da interação.

Na função antecipatória, as representações possuem seu próprio desenvolvimento em relação aos demais grupos, não se tem a preocupação de seguir o desenvolvimento de relações entre diferentes grupos, se adaptam ativamente.

\section{Abordagens da Representação Social}

A representação social teve desdobramentos, se dividindo em três abordagens, sendo elas a culturalista, societal e estrutural. Sá (1998) apresenta as três abordagens como correntes teóricas que não são teorias incompatíveis entre si, pois possuem uma mesma fundamentação base.

Cada abordagem foi desenvolvida pela concepção de diferentes autores, trazendo um aporte a teoria das representações sociais. Jodelet liderou a abordagem cultural, Willen Doise lidera a abordagem societal, Jean Claude Abric lidera a abordagem estrutural, que juntas se manifestam como importantes contribuições para a Teoria das Representações Sociais (Bertoni, Galinkin, 2017)

Almeida (2005) ao citar Jodelet (2000) apresenta que no desdobramento da teoria, a abordagem cultural está dividida entre duas dimensões: social e cultural, e por elas que se constituem as construções mentais e coletivas. As representações sociais são, procedimentos pelos quais os indivíduos interpretam seu mundo, sua vida e as suas dimensões. 
Para Jodelet (1989) a compreensão das representações sociais se constituem por meio dos elementos afetivos, sociais e mentais que se integram a cognição, linguagem e comunicação, afetando as representações da realidade social e material.

A teoria das representações sociais possui uma perspectiva antropológica e sociológica, se constitui de significações da cultura, sendo entendido como transmissora de referências simbólicas, se constitui por motivações, interesses entre sujeitos, se faz possível pelo convívio social entre as pessoas de um mesmo grupo, são acumulativas nos pensamentos e mente dos indivíduos. É portanto formado pela socialização e relações entre os sujeitos que pertence ao mesmo grupo (Triani, Bizerra e Novikoff, 2017).

Para Jodelet (2001-2005) é necessário compreender os discursos que criam as representações, analisando as suas práticas, através de informações, imagens, expressões faciais, crenças entre outras elementos que explicam e emerge núcleos figurativos. Por estes meios se originam as práticas da produção das representações.

Doise (2002) explica que a representação social tem como objetivo conectar o indivíduo ao seu grupo, promovendo uma dinâmica social e a construção de suas representações, traços de ideias, pensamentos, crenças sobre determinados objetos, fatos e fenômenos do cotidiano.

A abordagem societal, acredita que os sujeitos da sociedade são direcionados por dinâmicas sociais, em respeito a interação social, valores e crenças. Conforme Doise (2002) as representações sociais se compõem por princípios organizadores de relações simbólicas entre os indivíduos e grupo.

Esta abordagem societal segundo Doise (2002) se constitui de quatro processos de análise das representações sociais, a saber:

O primeiro é o individual, ele tem objetivo de analisar aspectos interindividuais, pela maneira que os indivíduos organizam suas experiências pela maneira em que vivem, este processo busca compreender de forma específica o modo que os sujeitos se organizam em sociedade.

O segundo, processo interpessoal, além de centrar-se em aspectos interindividuais relaciona-se também aos aspectos situacionais, buscando os princípios explicativos típicos, no sistema de interação.

O terceiro processo e o intergrupal, que analisa aspectos internos do grupo, são eles as diferentes posições que os indivíduos envolvem nas relações sociais e a maneira que articula nos dois processos anteriores, analisando as posições em que os indivíduos ocupam no relacionamento social.

O último processo, societal, analisa os sistemas de representações e crenças, que possibilita a significação dos comportamentos dos indivíduos, características da sociedade e dos grupos que se inserem, apresentam sentido ao comportamento apresentado pelo indivíduos.

A articulação entre os quatro processos, individual, interpessoal, grupal e societal, produz a conceituação da representação social, enfocando a interação social entre indivíduo e coletivo, permitindo explicações no âmbito psicológico e sociológico (Pacheco, 2011).

Doise (2002), pontua que a representação social se utiliza de três hipóteses para validação de suas pesquisas, sendo elas a difusão, propagação e propaganda. A difusão está baseada na variedade de indivíduos que pertencem ao mesmo grupo estabelecendo relações sociais, se comunicam e mantem a troca de simbologias e crenças, tornando-se comuns em determinados elementos. A propagação da representação, retrata as diferenças pessoais e individuais, mantendo diferentes relações, possuem variações no seu posicionamento pessoal, se identifica por meio dos princípios dos indivíduos com as suas variações sociais. A propaganda, relaciona as múltiplas ancoragens e relações coletivas, por mais que existe o consenso entre o sujeito para com a representação, também ocorre ancoragens de outras realidades, elas se constroem da relação entre as pessoas do grupo.

Segundo Nogueira e Di Grillo (2020), a abordagem estrutural, foi construída por meio da Teoria do Núcleo Central, elaborada por Jean Claude Abric, que propôs entender a estrutura da representação social, a partir da teoria de Moscovici, tendo 
como objetivo compreender o núcleo figurativo, analisando a estrutura interna, funciona como uma interpretação da realidade, trata das relações dos indivíduos com o meio/ambiente em que vive, meio físico e social, determinando seus comportamentos, o núcleo central surge a partir do pensamento social em todas as representações sociais.

Conforme Pavarino (2003), o núcleo central consiste na memória coletiva, permite a adaptação da realidade, este processo possibilita criar estabilidade as representações, removendo características contradições.

Para Abric (1998) toda representação social possui um núcleo central, que é desenvolvido por um conjunto de informações, sendo elas opiniões dos sujeitos, crenças, atitudes e propósito do objeto social, este é um elemento essencial que determina a organização de sua significação, a partir destas é elaborado um conceito com objetivo de apresentar uma visão subjetiva e social sobre a realidade.

Abric (2000) define as funções do núcleo central como: generadora, organizadora e estabilizadora. A primeira, transforma elementos que constituem as representações, permitindo criar um sentido ao indivíduo ou grupos. A função organizadora representa a ligação dos elementos que formam as representações sociais, constituem na composição destes elementos unificando-os. A terceira função é a estabilizadora, diferentes grupos não possuem as mesmas ideias se não compartilharem o núcleo central, pois é ele que determina a criação da representação. Desta forma, para que diferentes grupos possam ter a mesma representação social, o núcleo central deve ser compartilhado.

Abric (2000) contextualiza o papel do núcleo central dentro das representações sociais como esquemas centrais que dão sentido aos comportamentos. No entendimento de Sá (1996) o núcleo central possui as características de poder associativo, consensualidade, estabilidade e condicionalidade.

Segundo Wachelke (2012), o poder associativo refere que o núcleo central e seus elementos não são isolados, são conectados a outros e desta forma o sistema de núcleo central não se contradiz entre si, de forma que o sistema possui eficiência.

Abric (1994) afirma que, a consensualidade é portanto, a coesão das ideias e pensamentos do grupo, também permite a comunicação e relação social entre os integrantes.

Flament e Rouquette (2003), abordam que a estabilidade se divide em dois grupos, a sincrônica, que sucede quando os indivíduos do grupo mantem ativado os elementos centrais da representação, e a estabilidade diacrônica que está ligada a permanência dos elementos centrais no decorrer do tempo, que possibilita a antevisão do pensamento dos indivíduos no grupo a que pertence, estes são estáveis e podem se perder das ideias do grupo.

Moliner (1994) explica que a condicionalidade é um fator simbólico e está ligado ao objeto que antecede a formulação da representação, por meio de um laço privilegiado que se origina de condições sociais e históricas.

Abric (1994), pontua que é preciso identificar os componentes principais das ideias do grupo, sendo estes o conteúdo da representação social, a sua estrutura interna é o núcleo central, desta forma, o principal método de alcançar as representações sociais estabelecidas em determinado grupo é através de entrevistas, pesquisas e questionário de evocação de palavras.

\section{Considerações Finais}

Por meio da Teoria das Representações Sociais, é possível analisar o comportamento dos indivíduos, suas ideias, tradições e pensamentos, não é algo engessado e inflexível, as representações são constantes e se estabelecem de formas distintas no decorrer da vida dos indivíduos que compõem determinados grupos.

O processo de elaboração da representação social se estabelece a partir da tradução das questões que são abstratas para reais, tornando-as comuns e naturais, o que era subjetivo ganha sentido e passa a ser entendido como verdade e assim se familiariza a outras ideias similares já constituída pelo indivíduo. O conhecimento é produzido por meio dos pensamentos existentes e quando compartilhados, se tornam comuns e característicos, o pensamento semelhante permite compreender fatos, objetos ou fenômenos. 
O presente artigo pôde confirmar que a Teoria das Representações Sociais é uma abordagem dinâmica, com metodologia rica que permite conhecer o pensamento coletivo, tornando palpável o que até então era desconhecido, possibilitando aos profissionais uma melhor compreensão quanto aos grupos que sejam objetos de estudo, qualificando as possíveis intervenções.

A utilização desta teoria possibilita a investigação de situações específicas de determinados grupos, bem como o processo de criação de conceitos, podendo contribuir para intervenções focadas. Entre os estudo onde a teoria das representações sociais podem atuar de forma positiva podemos destacar os realizados com população de mulheres chefes de família na compreensão da qualidade de vida em situação de pandemia mundial, a compreensão quanto o que representa para as mesmas o mercado de trabalho, acesso a bens e serviços e muitos outros que apresentam a oportunidade de compreendermos a articulação entre o saber cientifico e o conhecimento de senso comum que os grupos sociais estabelecem e a maneira como os mesmos interferem em seus comportamentos.

\section{Referências}

Abric, J. C. (1994). Représentations sociales: aspects théoriques. In J. C. Abric (org). Pratiques sociales et representations. PUF, 11-36.

Abric, J. C. (1994). "Les représentations sociales: aspects théoriques”. In: Abric, J. C. (dir). Pratiques sociales e représentations. Presses de France.

Abric, J. C. (1994). Prácticas sociales y representaciones. Presses Universitaires de Frances.

Abric, J. C. (1994). Pratiques sociales et représentations. Presses Universitaires de France.

Abric, J. C. (1998). A abordagem estrutural das representações sociais. In. A S. Moreira \& D. C. Oliveira (eds). Estudos interdisciplinares de representação social. Ed. AB.

Abric, J. C. (2000). A abordagem estrutural das representações sociais: In: Moreira, A. S. P. \& Oliveira, D. C. (org). Estudos interdisciplinares de representação social. AB, 2, 27-37.

Almeida, A. M. O. (2005). A pesquisa em representações sociais: proposições teórico metodológicas. In: Santos, M. F. S. Almeida, L. M. de. Diálogos com a teoria das representações sócias. UFPE.

Almeida, A. M. O., \& Santos, M. F. S.(2011). A Teoria das Representações Sociais. In: Torres, C. V.; Neiva, E. R. (Org.). Psicologia Social: principais temas e vertentes. Artmed.

Almeida, J. G. O. (2018). Ciências sociais e representações: estudo dos fenômenos representativos e processos sociais, do local global. Revista Sociedade $e$ Estado, 33 (2).

Arruda, A. (2002). Teoria das representações sociais e teorias do gênero. Cadernos de pesquisa. 117, 127-147.

Bertoni, L. M., \& Galinkin, A. L. (2017). Teoria e métodos em representações socias. Ilhéus, BA.

Bertoni, L. M., \& Galinkin, A. L. (2017). Teoria e métodos em representações sociais. In: Mororó, L. P., Couto, M. E. S., \& Assis, R. A. M. Notas teóricometodológicas de pesquisa em educação: concepções e trajetórias. Ilhéus, BA: EDITUS, 101-122.

Canetti, E. (1995). Massa e poder. Companhia das Letras.

Carvalho, C. A., Ribeiro, L. P., \& Antunes-Rocha, M. I. (2017) Representações sociais em movimento: uma análise de duas pesquisas no âmbito da educação do campo da FAE-UFMG. Revista Educação e Cultura Contemporânea. 14 (37), 343-366.

Danhke, G. L. (1989). Investigación y comunicación. In: Fernandez-Collado, C., Danhke, G. L. La comunicación humana: Ciencia Social. México: Mcgrawhill, 385-454.

Doise, W. (1976-84). A Articulação Psicossociológica e as Relações entre Grupos. Moraes Editores: Lisboa (tradução portuguesa de: L'Articulation Psychosociologuique et les Relations entre Groupes, Éditions A. de Boeck, Bruxelles).

Doise, W. (2002). Direitos do homem e força das ideias. horizonte.

Duran, M. C. G. (2006). Representações sociais de professores em formação sobre profissão docente. In: Souza, C. P.; Pardal, L. A.; Villas Boas, L. P.S. Representações sociais sobre o trabalho docente. Aveiro: Universidade de Aveiro, 91-106.

Durand, G. (1984). Les structures anthropologiques de l'imaginaire. (10a ed.), Dunod. Jodelet, D. (1989). Les représentations sociales. PUF.

Durkheim, E. (1987). As regras do método sociológico. Companhia Editora Nacional.

Farias, D. L. G., Silva, A. M. B. S., JR, P. L. D., \& Medeiros, L. T. (2020). Representações sociais dos professores do nível superior sobre o estresse ocupacional. Rio de Janeiro, Brasil.

Ferreira, A. B. H. (1975). Novo dicionário Aurélio da Língua Portuguesa. Nova Fronteira. 
Flament, C., \& Rouquette, M. L. (2003). Anatomie des idées ordinaires. Comment étudier les représentations sociales. Armand Colin.

Freud, S. (1979). Psicología de las masas y análisis del yo. In S. Freud. Trabalho original publicado em 1921. 1(18).

Freud, S. (2011). Psicologia das massas e análise do eu. In. S. Freud. Trabalho original publicado em 1921. Companhia das Letras, 15.

Gustave, L. B. (2008). Psicologia das Multidões. Cunha, MS. (Trad.) São Paulo: Martins Fontes. (Publicado originalmente em 1895).

Jesuíno, J. C. (2000). A psicologia social europeia. Fundação Calouste Gulbenkian.

Jodelet, D. (1989). Représentations sociales: um domaine en expansion. In: Jodelet, D.. (Ed). Les représentations sociales. PUF, 31-61.

Jodelet, D. (1994). "Représentations sociales: um domaine em expansion”. In: Jodelet, D. (dir). Les représentations sociales. Presses Universitaires de France (Sociologie d'Aujourd'hui), 4.

Jodelet, D. (2001-2005). Representações sociais: um dominio em expansão: In: Jodelet, D. Representações sociale. EDUERJ, 2, 17-44.

Jodelet, D. (2005). Loucuras e representações sociais: Editora Vozes.

Lefebre, H. (1968). Ideologia e Marx. Forense.

Lima, R. C. P., \& Campos, P. H. F. (2020). Núcleo figurativo da representação social: contribuições para a educação. Educação em Revista, 36.

Mazzoti, A. J. A. (1994). Representaçoes sociais: aspectos teóricos e aplicações à educação. 14 (61).

Mcdougall, W. (1920). The group mind. Cambridge: Cambridge University Press.

Milgram, S., \& Toch, H. (1969). Collective behavior: crowds and social movements. In G.

Minayo, M. C. S. (1996). O desafio do conhecimento: pesquisa qualitativa em saúde. HUCITEC - ABRASCO.

Moliner, P. (1994). Les méthodes de répérage et d'identification du noyau des representations sociales. In: Guimelli, C. (org). Structures et transformations des representations sociales. Lausanne: Delachaux et Niestlé, 199-232.

Moscovici, S. (1961). La psychanalyse, son image et son public.

Moscovici, S. (1976). La Psicanalyse, son image et son public. Presse Universitaire de France.

Moscovici, S. (1978). A representação social da psicanálise. Tradução de Cabral. Zahar.

Moscovici, S. (1978). La representación social del psicoanálisis. Traducción de Álvaro Cabral. Zahar.

Moscovici, S. (1982). The coming era of representations. In. Codol, J. P. \& Leyens, P. (Eds). Cognitive analysis of social behavior. The Hague: Martinus Nijhoff, $115-150$.

Moscovici, S. (1994). Textos em Representações Sociais. In: Jovchelovitch, S., Guareschi, P. (org). Vozes.

Moscovici, S. (2001). Das representações coletivas às representações sociais. In: Jodelet, D. (org). Representações Sociais. Eduerj, 45-66.

Moscovici, S. (2003). Representación social: investigación en psicología social. Voces.

Moscovici, S. (2005) Representações sociais: investigações em psicologia social. Vozes, 3.

Moscovici, S. (2012). A psicanálise, sua imagem e seu público. Vozes.

Nogueira, K., \& Grillo, D. M. (2020). Teoria das Representações Sociais: história, processos e abordagens.

Oliveira, M. (1999). Representações sociais e simbolismo: os novos rumos da imaginação na sociologia brasileira”. In: Revista de ciências humanas. Curitiba: Editora da UFPR, 173-193.

Pacheco, J. G. (2011). Representações sociais da loucura e práticas sociais: o desafio cotidiano da desinstitucionalização. (Tese de Doutorado). Instituto de Psicologia, Universidade de Brasília.

Pavarino, R. N. (2003). Teoria das Representações Sociais: Pertinência para as pesquisas em Comunicação de massa. XXVI Congresso Brasileiro de Ciências da Comunicação- BH/MG. Universidade Católica de Brasília: Intercom - Sociedade Brasileira de Estudos Interdisciplinares da Comunicação.

Pereira, A. S. (2018). Metodologia da pesquisa científica. UFSM.

Piaget, J. (1959). Aprendizagem e conhecimento. Freitas Bastos, 1975.

Ribeiro, L. P., \& Rocha, M. I. A. (2021). Identidade e representações sociais: evidências e correlações a partir de pesquisa da área da educação. Revista Educação e Cultura Contemporânea, 18 (52), 402-435.

Sá, C. P. (1996). Núcleo central das representações sociais. Vozes.

Sá, C. P. (1998). A construção do objetivo de pesquisa em representações sociais. EDUERJ. Durand, G. (1984). La foi du cordonnier. Denoel. 
Research, Society and Development, v. 10, n. 6, e38610615881, 2021

(CC BY 4.0) | ISSN 2525-3409 | DOI: http://dx.doi.org/10.33448/rsd-v10i6.15881

Sampieri, R. H., Collado, C. F., \& Lucio, P. B. (2006). Metodologia de pesquisa. Mcgraw-hill, 3.

Tomé, A. M., \& Formiga, N. S. (2020). Abordagens Teóricas e o uso da análise de conteúdo como instrumento metodológico em representações sociais. Revista Psicol Saúde e Debate, 6 (2), 97-117.

Triani, F. S., Bizerra, C. C., \& Novikoff, C. (2017). A influência da cultura sobre as representações sociais. Revista Educação e Cultura Contemporânea. 14 (36), 7-21.

Vygotsky, L. S. (1989). Pensamento e linguagem. Martins Fontes.

Vygotsky, L. S. (1999). A formação social da mente. Martins Fontes.

Wachelke, J. (2012). Context effects and inter-representations activation: na experimental study. Papers on social representations. 